\title{
A scoping review of physical activity measurement tools in free-living conditions
}

\section{Prošireni pregled sredstava za mjerenje tjelesne aktivnosti u normalnim životnim uvjetima}

\author{
Pavol Nechvátal ${ }^{1 *}$, Anna Eliášová2 ${ }^{2}$ Alexander Kiško ${ }^{1}$, L'ubica Derňárová², \\ Ĺuboslava Kundraciková2,3
}

${ }^{1}$ Department of Physiotherapy, Faculty of Health Care, University of Prešov, Slovak Republic

${ }^{2}$ Department of Nursing, Faculty of Health Care, University of Prešov, Slovak Republic

${ }^{3}$ Student of Nursing, St. Elizabeth University of Health and Social Work, Bratislava, Slovak Republic

\author{
*Corresponding author: \\ Mgr. Pavol Nechvátal, PhD. \\ Faculty of Health Care, University of Prešov \\ Partizánska 1, 08001 Prešov \\ Slovak Republic \\ e-mail: pavol.nechvatal@unipo.sk
}

Abstract. Accurate assessment of physical activity becomes essential in terms of health outcome and effectiveness of health-enhanced intervention programmes. This paper systematically describes and compares up-to-date methods to assess habitual physical activity and discusses main issues regarding the use and interpretation of data collected with these techniques in free-living conditions. A search strategy was employed using PubMed Central database with limits set to include articles from 2007 to 2017. Data were reviewed, extracted and assessed by two researchers, with disagreements being resolved by a third researcher, with their respective definition, usual applications, advantages, and shortcomings. It is concluded that no single current technique is able to quantify all aspects of physical activity under free-living conditions, requiring the use of complementary methods. A validated questionnaire is usually the preferred method in free-living conditions for population-based samples, but when measuring effects this should be combined with an objective measurement instruments. The choice of method depends predominantly on the aim of the measurement, and the availability of personnel, time and financial resources.

Key words: accelerometry; global positioning systems; heart rate; observation; physical activity

\begin{abstract}
Sažetak. Točna procjena tjelesne aktivnosti postaje neophodna u smislu zdravstvenog ishoda i učinkovitosti zdravstvenih intervencijskih programa. Rad sustavno opisuje i uspoređuje trenutne metode procjene uobičajene, svakodnevne, fizičke aktivnosti. Raspravlja o glavnim pitanjima vezanim uz korištenje i tumačenje podataka prikupljenih pomoću ovih tehnika u slobodnim životnim uvjetima. Upotrijebljena je strategija pretraživanja pomoću PubMed Central baze podataka, uključujući isključivo članke od 2007. do 2017. godine. Podatke s njihovom pojedinačnom definicijom, uobičajenom primjenom, prednostima i nedostatcima, izdvojila su, pregledala i procijenila dvojica istraživača. Postojala su određena neslaganja koja su riješena uključivanjem trećeg istraživača. Postignut je zaključak da niti jedna od suvremenih tehnika nije sposobna kvantificirati sve aspekte fizičke aktivnosti u uvjetima svakodnevnog života te se stoga razloga moraju koristiti komplementarne metode. Valjani upitnik obično je prioritetna metoda u uvjetima normalnog života populacijskih uzoraka, ali kod mjerenja efekata treba ga kombinirati s objektivnim instrumentima mjerenja. Odabir metode ovisi prije svega o cilju mjerenja i dostupnosti osobnih, vremenskih i financijskih izvora.
\end{abstract}

Ključne riječi: akcelerometrija; broj otkucaja srca; globalni pozicijski sustavi; promatranje; tjelesna aktivnost 


\section{INTRODUCTION}

With changing social and economic patterns all over the world, sedentary lifestyles have become a worldwide phenomenon. Sedentary lifestyles are associated with increased obesity, type 2 diabetes, and cardiovascular disease, and hence the promotion of active lifestyles is an important public health priority. As it is stated in WHO (World Health Organization) "Physical activity strategy for the WHO European Region 20162025" EU (European Union) Member States should make supporting research a priority in order to strengthen the evidence base on effective and efficient interventions to promote physical activity and appropriate government policy instruments on physical activity, including intersectoral approaches ${ }^{1}$. To monitor trends and evaluate public health or individual interventions aiming at increasing levels of physical activity, reliable and valid measures of habitual physical activity are essential. With measurement of physical activity becoming more common in preventive health care, it is imperative that healthcare professionals become more knowledgeable about the different methods available to objectively measure physical activity behaviour. A variety of techniques exist to quantify levels of habitual physical activity during daily life, including subjective self-reports of physical activity by diaries or logbooks (PA-log) methods and physical activity questionnaires, as well as objective measures such as doubly labeled water (DLW) technique, direct observation, heart rate monitoring, pedometry, accelerometry ${ }^{2}$. Objective measures do not rely on information provided by the patient, but instead measure and record the biomechanical or physiological consequences of performing physical activity, often in real time. As such, objective measures are not subject to the reporting bias or recall problems associated with self-report methods ${ }^{3}$. Up-to-date systematization of methods and definitions is essential for the improvement of knowledge in the area. The purpose of this article was to provide an overview of the different methods used to measure physical activity in free-living conditions. The PubMed Central database was searched using the following keywords: physical activity measurement in combination with questionnaire, doubly labeled water, direct observation, heart rate monitoring, pedometry, accelerometer/accelerometry, smartphones and global positioning systems (GPS). Limits were set to include articles from 2007 to 2017. Data describing measurement methods and properties were extracted and reviewed by two researchers, with disagreements being resolved by a third researcher.

The IPAQ instruments have acceptable measurement properties, at least as good as other established self-reports. IPAQ has reasonable measurement properties for monitoring levels of physical activity among adults in diverse settings. The IPAQ-SF is recommended in population samples, when IPAQ-LF is preferable for research requiring more detailed assessment.

\section{QUESTIONNAIRE METHODS}

Self-reports of physical activity by a diary or log method provide a detailed record of an individual's physical activity on a daily basis; these records are generally self-completed prospectively on paper or computer, in form of interview, daily logs or diaries. Strengths of self-reports include low cost of administration, ability to measure large samples, availability of many instruments with evidence of reliability and validity, and ability to tailor the measure to the population and study goals. Individual bouts of activity are recorded in diaries as they occur during the day typically in 15 minute segments that may lead to the omission of some activities, but reducing the period has been shown to be too intensive and lead to non-completion. In contrast, logs capture the time individuals spend in broad categories of activity: inactive, sitting, light, moderate, vigorous and very vigorous and examples of activities in each intensity level are provided ${ }^{4}$. In diaries, individuals are asked to record their activity often from a pre-defined list which is coded, but space is provided for other activities to be recorded. The list of activities is typically grouped according to their metabolic equivalents (METs) value. The intensity of the activity (low, moderate or vigorous) is also recorded. Weaknesses of the 
method include well-documented inaccuracies, the tendency to over-report activity levels, use of unfamiliar terms on surveys (e.g., moderate and vigorous intensity), inability to use with young children, and inability to compare results across studies due to the large number of measures available. Interviewer-administered surveys are probably needed with low-literacy participants, but they are more expensive to use and require training of interviewers. Diaries produce more detailed information i.e. types of activity, intensity and patterns, but are more burdensome for individuals to complete and the data are more complex to reduce and enter. Correlations with accelerometry were moderate and ranged from 0.26-0.54 depending on the comparisons. The log book is less burdensome than others. The development of personal digital assistants has enabled this electronic medium to be utilised for the collection of physical activity data by a diary method. An electronic version of the revised adult compendium of physical activities is available. Physical activity self-reports mainly assessed leisure or recreational activities, but adults can also be active in their jobs, through the type of transportation they use, and in performing household chores ${ }^{5}$.

The International Physical Activity Questionnaire (IPAQ) was developed to address these concerns by a group of experts in 1998 to facilitate surveillance of physical activity based on a global standard $^{6}$. The IPAQ assesses activities in all multiple domains among adults aged 18 to 65 over the previous week and is adaptable to all cultures and languages in almost 70 countries and has been shown to be as reliable and valid as other self-reports. The IPAQs are the most practical subjective self-report instruments in physical activity research?. Unfortunately, due to their subjective nature, these instruments are inherently limited by factors such as recall error, social desirability or gender bias, floor effects, misinterpretation of terminology, and some questionnaires fail to quantify the totality of physical activity dimensions and contexts. However, some advantages to using questionnaires over other self-reporting instruments exist: low cost, applicable to a wide range of ages and in a large number of people, recall does not alter current behaviour under study and measures can be adapted to fit the needs of a particular population or research question. Recent reviews have documented 85 self-administered physical activity questionnaires in a several forms of administration (face-to-face, telephone interviews, mailed forms ${ }^{8}$. There is a clear lack of systematization and standardization of questionnaires and no one of them was superior and therefore could not be strongly recommended above others ${ }^{9}$. Several countries have adopted the IPAQ as their national or regional surveillance system, and these data contribute to current WHO and European surveillance systems ${ }^{10,11}$.

The IPAQ has since become the most widely used physical activity questionnaire, with two versions available: the long form (IPAQ-LF) and the short form (IPAQ-SF). Both of them involve 7-day recall of physical activity. The IPAQ-SF records the activity of four intensity levels: 1) vigorous-intensity activity such as aerobics, 2) moderate-intensity activity such as leisure cycling, 3) walking, and 4) sitting, in part because the burden on participants to report their activity is small. It was designed for use in surveillance studies to estimate the time spent performing physical activities (moderate to vigorous) and inactivity (time spent sitting). The IPAQ-SF can be used to successfully estimate VO2max as well as submaximal exercise tests. It was concluded that highly active participants could be correctly identified, and distinguished from inactive participants using the IPAQ-SF, but other discrimination was poor. A limitation is that the IPAQ-SF does not provide summaries by domain; however, the slightly longer Global Physical Activity Questionnaire (GPAQ) does summarize activities by recreation, occupation, and transportation domains.

The correlation between the IPAQ-SF and objective measures of activity or fitness in the large majority of studies was lower than the acceptable standard. Furthermore, the IPAQ-SF typically overestimated physical activity as measured by objective criterion by an average of 84 percent. Hence, the evidence to support the use of the IPAQ-SF as an indicator of relative or absolute physical activity is weak ${ }^{12}$. 
The IPAQ-LF was developed to obtain internationally comparable data on health-related physical activity and was designed to provide a comprehensive evaluation of daily physical activities, and assesses the time spent walking, doing moderate intensity and vigorous-intensity activity within the domains of work, transportation, domestic and gardening activities, and leisure-related activities. Reliability and validity results for it showed correlations with motion detectors of 0.30-0.33. Later, a revised IPAQ-LF version has been launched. As different from the first, the revised version does not aim to measure low-intensity physical activity. It asks in detail about walking, moderate-intensity and vigorous-intensity physical activity in each of the four domains. Data collected with the IPAQ-LF can be reported as a continuous measure and reported as median METs-minutes. Also GPAQ is a suitable and acceptable instrument for monitoring physical activity in population health surveillance systems ${ }^{13}$. Self-report questionnaires relatively inexpensive, allow researchers to estimate physical activity in large number of individuals while maintaining low burden to investigator and respondent.

Some of the Activity Significance Personal Evaluation Scales are brief, easily administered assessments of the contribution of everyday activities to personal health and wellness. These scales may facilitate occupational therapy practice by enabling clinicians to assess changes in meaning of an activity over time ${ }^{14}$.

Nevertheless, a majority of intervention studies to help increase older adult physical activity used self-report measures, even though many have little evidence of validity and reliability. It was recommend that future researchers utilise valid and reliable measures of physical activity with wellestablished evidence of psychometric properties such as hip-accelerometers and the Community Health Activities Model Program for Seniors (CHAMPS) Physical Activity Questionnaire for Older Adults ${ }^{15}$.

Physical activity questionnaires that have been developed and validated in nonpregnant adults have failed to include household or childcare activities, which comprise a substantial proportion of activities during pregnancy. Inaccurate deter- mination of the daily physical activity level may lead to misunderstandings about the correlations between its during pregnancy and both maternal and fetal health. The Pregnancy Physical Activity Questionnaire (PPAQ) is recommended tool for the assessment and measurement of physical activity levels amongst pregnant women. The PPAQ is a quick and simple method to evaluate the duration, frequency, and intensity of activity patterns in pregnant women. It has been included in both epidemiological and clinical studies. The

Pedometers can provide feedback about the amount of daily physical activity, and have been promoted as effective tools to monitor it in healthy population. Simple health-enhance interventional programmes using pedometers can effectively improve free-living physical activity levels.

PPAQ has already been translated into different languages, and it is available in Turkish, Japanese, Vietnamese, and French ${ }^{16}$.

Expert focus groups and cognitive testing studies showed substantial problems with regards to understanding different physical activity intensity levels, to indicate durations of routine activities such as walking or sitting, and to combine multiple activities to provide the total amount of activities. Consequently, the EHIS Core Group (a group of national health survey experts) commissioned development of the European Health Interview Survey-Physical Activity Questionnaire (EHIS-PAQ), a short, domain-specific physical activity questionnaire, which allows for the estimation of indicators for total, work-related, transportation-related, and health-enhancing leisure-time physical activities. Notwithstanding some degree of measurement error associated with the EHIS-PAQ, it was conclude that the questionnaire quantifies physical activity and its sub-domains with sufficient validity for use in surveillance studies to inform public policy on this issue ${ }^{17}$.

10 studies have evaluated the measurement properties of current self-report physical activity questionnaires (SRPAQs) completed within healthy adult populations. The 1 week Godlin-Shephard 
recall demonstrated 'moderate' validity with the gold standard measure of accelerometry $(r=0.43)$. Authors conclude that further investigation of criterion validity of SRPAQs is required ${ }^{18}$.

Overall, self-report measures of physical activity are limited by factors including social desirability, recall bias, and variations in cognitive, psychometric properties and memory processes depending on several factors including age, education, occupational status, and socioeconomic position.

Limitations are the subjective types of measures, recall errors, deliberate misrepresentation, social desirability or other biases, especially when dealing with children and seniors. A further limitation of many self-report measures, including IPAQ, is that they have not been shown to be sensitive to changes in interventions and may be more appropriate for estimating the prevalence of physical activity in the population as are well suited to large surveillance studies.

In practice, some of the questionnaires may not identify almost $50 \%$ of patients who should be advised to increase their physical activity. Therefore, physicians should advocate that all of their patients adopt an active lifestyle, including the achievement of $\geq 150$ minutes of moderate-tovigorous physical activity weekly ${ }^{19}$.

\section{Doubly labeled water method}

Among the objective measures of physical activity the DLW technique is a highly accurate and objective technique for assessing total daily energy expenditure. The use of DLW method to assess free-living energy expenditure is currently regarded as the gold standard technique. With a reported precision of $\pm 3 \%$, this method serves as a reference for validating other instruments or methods designed to measure energy expenditure. With this method a person drinks a standardized amount of the two stable isotopes deuterium and oxygen-18, which compose DLW, and is allowed to return to a normal lifestyle with only urine samples collected at the beginning and end of the measurement period. By measuring elimination kinetics of isotopes from person's body, total carbon dioxide production is determined for a measurement period, and, ultimately, an estimation of total daily energy expenditure.
This method can be carried out on a wide range of individuals over lengthy time period, usually between 4 and 21 days, which is advantageous for capturing habitual energy expenditure patterns. However, the cost of materials and expertise required to analyse the isotope concentrations via mass spectrometry prohibits the use of DLW in large epidemiological studies, it remains too costly to be considered practical for large-scale studies and is impractical in non-research clinical settings.

\section{DIRECT OBSERVATION METHODS}

Direct observation is used most often for assessing physical activity of groups in specific settings, such as physical education classes, school recess, and parks. Advantages of direct observation include high quality data, ability to record numerous dimensions of physical activity, and flexible scoring of results. Disadvantages are the expense of human observers, need for training, difficulties of managing and scoring the data, and possible reactivity effects of the observations on participant behaviour. Two widely used observation measures illustrate the method's use. The System for Observing Fitness Instruction Time (SOFIT) was developed to evaluate physical education classes and has been used to evaluate numerous physical education programs for research and non-research purposes. The System for Observing Play and Recreation in Communities (SOPARC) was designed to evaluate how recreation settings are being used. The context of the physical and social environment can be coded, including main type of activity, supervision, equipment, weather, and can be used to evaluate both programs and environmental interventions.

It was currently concluded that trained observers can reliably use the 12 -button counter to accurately assess physical activity distribution and disparities by age and gender ${ }^{20}$.

\section{HEART RATE MONITORING}

Heart rate monitoring is a measure of a direct physiological response to physical activity to estimate the intensity of activity for people across the age range. The most common used heart rate monitors (HRMs) can detect just about any type of activity, and they can even be used for activi- 
ties in the water. The development of minute by minute HRMs with internal capacity for multiple days' storage without displaying heart rate has increased the feasibility of this objective measure of physical activity with high reproducibility within subjects. HRMs have been widely used to quantify physiological stress, but their efficacy at low intensities has been questioned due to the potential interference of environmental conditions and emotional stress.

A single device that simultaneously collects synchronized heart rate and motion $(\mathrm{HR}+\mathrm{M})$ data is preferable in order to overcome the inherent limitations. The HR+M monitors compensate for the limitations of separate devices so that all types of activities can be assessed throughout the range of intensities, including sedentary behaviours. Incorporated software allows that individual calibrations based on an individual's heart rate response can be applied to the $\mathrm{HR}+\mathrm{M}$ data. The devices are simple to carry, equipment needs are minimal and inexpensive, and they can be performed almost anywhere by non-experts. Some users are concerned about the monitors creating reactivity among participants, or changes in behaviour caused by the measurement. Most studies indicate activity monitoring does not create much reactivity. However, it may depend on the specific monitor ${ }^{21}$.

Currently it was concluded that both heart rate monitoring and accelerometry may be used to estimate energy expenditure in adult European men and women, with improved precision if combined and if heart rate is individually calibrat$\mathrm{ed}^{22}$.

\section{PEDOMETRY}

Pedometers are small, belt-mounted devices primarily used for quantifying the daily number of steps accumulated, which is the most common activity. Pedometers are easy to use for participants and evaluators, and they accurately assess walking. They are less useful for running, cycling, and water activities and they work less well for young children who do a variety of activities and for older adults who walk too slowly for accurate measurement. Pedometers provide an inexpensive overall measure of physical activity but are unable to assess intensity, frequency and duration of activity or to estimate energy expenditure. Some devices can also record the covered distance after the precise setting of the step length, as well as to count the calories expenditure and the amount of the burned body fat.

In few studies pedometers correlated highly in terms of both criterion (direct observation) and convergent validity (heart-rate monitor, accelerometer) and can be effectively utilized as a valid determinant of physical activity levels among children and adolescents, particularly in largescale epidemiological studies ${ }^{23}$.

Pedometers serve as motivational tools for promoting physical activity because immediate feedback on accumulated steps, whether incidental or intentional, provides goal attainment information and is a constant reminder to be active ${ }^{24}$. Some types of the pedometers significantly underestimate steps per day under free-living conditions $^{25}$ and it is advised to use them only when physical activity is continuous or intermittent and moderate to high ${ }^{26}$. On the other hand, Scruggs ${ }^{27}$ in his original research shows pedometry to be an assessment tool for researchers and practitioners and has demonstrated acceptable decision accuracy when assessing physical activity. Some devices can also record the covered distance after the precise setting of the step length, as well as to count the calories expenditure and the amount of the burned body fat. Minimum numbers of days required for estimating habitual physical activity levels in children using a pedometer were five during weekdays. However, estimating habitual physical activity levels during weekends, and weekdays and weekend days combined was impractical ${ }^{28}$.

\section{ACCELEROMETRY}

Accelerometry is the most common objective method used to measure physical activity, it has been used extensively in field settings to monitor activity patterns in subjects of various age $\mathrm{e}^{29,30}$. Accelerometer is one movement sensor capable of measuring light-intensity physical activity and sedentary behaviour objectively. As its name suggests, the device measures accelerations. Technological advances have made the device smaller, 
lighter, discrete to wear and less expensive (e.g., the Actigraph GT3X+ model, used in the case study of the Women's Health Study (WHS), costs $\$ 200-\$ 250)$. Thus, the accelerometer has now become feasible for use in various research and clinical conditions and settings ${ }^{31}$.

Acceleration is measured by piezoelectric or seismic sensors in one (longitudinal body axis, usually vertical), two (vertical and medio-lateral or vertical and anterior-posterior) and three (vertical, mediolateral and anterior-posterior) directions. The device is typically attached to the hip, waist or wrist by a strap. Accelerometers attached to the waist do not capture upper body movement or cycling, and underestimate walking on an incline or carrying heavy loads. Physical activity measurements recorded by a chest worn accelerometer more closely resembled activity measurements recorded at the waist site than when compared to the wrist site. When combined with high chest site preference, the findings suggest that the chest is a feasible site for accelerometer wear ${ }^{32}$. A cross-sectional study collecting data from accelerometerassessed physical activity using hip- vs wrist-worn devices in free-living environment showed a moderate correlation in older, free-living women ${ }^{33}$.

Accelerometers provide physical activity measurements such as activity counts and vector magnitude, energy expenditure, steps taken, activity intensity levels, METs and more. Most of the devices collect data in raw format at a user specified sample rate up to 100 Hertz. Filtering and epoch selection are performed after data is collected, allowing users to process datasets multiple times at different epoch selections even after a study has ended. Latest models have an inclinometer to determine subject position and identify periods when the device has been removed, and it can be worn during periods of sleep to measure the amount and quality of sleep. Some accelerometers can store over 40 days of raw data, having a rechargeable battery capable of providing power for 30 days between charges. Few models are waterproof and can be used for evaluating of water-based activities. The accelerometers appear to be a useful tool for measuring energy expenditure under free-living conditions for both short- and long-term periods ${ }^{34}$. Deter- mining the number of days to reliably assess habitual physical activity and sedentary behaviour and minimizing participant burden remains a challenge. It was determined that 3-4 days of monitoring are needed to assess habitual physical activity regardless of which instrument is selected. Despite nostatistical differences between days for total physical activity by the accelerometer and pedometer, the magnitude of differences between days suggests that day of the week cannot be completely ignored in the design and analysis of physical activity studies that involve < 7-day monitoring protocols for these instruments. If specific intensities of physical activity are an outcome of interest, additional days may be needed for the PA-log but not the accelerometer. For sedentary behaviour, any 5 days of monitoring will provide a reliable estimate of behaviour $^{35}$. It was also suggested that using accelerometer wear time criteria of $12 \mathrm{~h} /$ day or less may underestimate step count and time spent in various physical activity levels ${ }^{36}$.

The primary outcome measure of accelerometry is body acceleration, often expressed as a count value. Secondary outcomes are estimates of bout frequency, duration and intensity of body movement. It has been suggested that establishing the relationship between activity counts and energy expenditure is sometime problematic. Additionally, an accelerometer placed on one body location does not capture all activity of other body sites, although there is usually some cross-correlation. Cut-points for defining different intensity levels are somewhat arbitrary and the use of different cut points can have profound impact on the estimate of the physical activity. Laboratoryderived physical activity energy expenditure equations are not all equally suitable to assess physical activity in free-living populations. Laboratory-derived prediction equations have been found to overestimate free-living energy expenditure by $47 \%$ in a study using DLW technique ${ }^{37}$. Common for accelerometry is that linear relationships derived for rest and ambulation display much poorer validity in biomechanically diverse activities, e.g. cycling or lifting weights. Advanced statistical methods have been proposed to improve prediction equations. During the past dec- 
ade the objective assessment of physical activity using accelerometer-based devices has demonstrated substantial potential, especially in documenting the pattern of light-, moderate-, and vigorous-intensity activity throughout the day.

While accelerometers provide objective measurements, it is important to note some limitations. They primarily measure locomotor activity when worn over the hip (typical placement position), and so miss upper body movement. Further, they cannot distinguish whether a person is carrying any weight (e.g., walking carrying a heavy bag expends more energy vs. walking with no load). Accelerometers do not inform on body posture; thus, they cannot distinguish between sitting and standing still. Since participants are older, accelerometer indications of very low levels of activity over long periods during waking hours likely indicate sitting, and not standing with little movement ${ }^{38}$. Although these devices do not provide information on activity type, location or context ${ }^{4}$, data support the use of the accelerometer as an accurate tool to estimate free-living physical activity, at least within those frequencies that are common to most types of human daily activities $^{39}$.

Recent technological advances have made the use of accelerometer feasible for use in longitudinal, large-scale epidemiological studies that intend to investigate the associations of objectively measured physical activity or sedentary behaviour with hard clinical outcomes. Logistical challenges exist in collecting objectively measured physical activity or sedentary behaviour data from large-scale epidemiological studies, which result in a reduced number of participants available for investigation. While large amounts of data can be collected using accelerometers, procedures to reduce and process these data are not well developed; thus, best practices and standards for accelerometer data reduction and processing are needed ${ }^{38}$. Also there is large heterogeneity across studies in the explained variance of activity-related energy expenditure when estimated based on accelerometry and these need to be interpreted cautiously ${ }^{40}$.

As physical activity monitoring moves into the future, it is incumbent on researchers to be open to new technologies, such as multisensory arrays, as well as integrating familiar sensors into new devices. To improve health outcomes it is critical to accurately measure physical activity and sedentary time spent in- and outdoors. The location in which physical activity and sedentary behaviour are performed can provide valuable behavioural information, both in isolation and synergistically with other areas of physical activity and sedentary behaviour research. GPS have been used in physical activity research to identify outdoor location; however, while GPS can receive signals in certain indoor environments, it is not able to provide room- or subroom-level location. On average, adults spend a high proportion of their time indoors. A measure of indoor location would, therefore, provide valuable behavioural information. The critique technologies which have been or could be used to assess the location of physical activity and sedentary behaviour are GPS, real-time locating systems, wearable cameras. Real-time locating systems determine the indoor location of a wearable tag via the known location of reference nodes. Although the type of reference node and location determination method varies between manufacturers, Wi-Fi (technology for wireless local area networking) appears to be the most popular method ${ }^{41}$.

GPS devices linked with physical activity monitoring devices enables measurement of where and when individuals are active as well as their energy expenditure and are a promising tool for improving understanding of the spatial context of physical activity ${ }^{42}$. If the validity, reliability, and feasibility of wearable GPS/ Geographic Information System (GIS) and socio-economic status (SES) analyzing devices are better understood, these devices can become important measurement tools in physical activity research ${ }^{43}$.

Rapid developments in technology have encouraged the use of smartphones in health promotion research and practice. All major cell phone manufacturers are already building activity monitors into cell phones, with the cell phone service providing the data download. The iPod/iPhone's built-in accelerometer as a measurement of physical activity in order to create a better physical activity recognition program is currently 
tested $^{15}$. The introduction and integration of accelerometry and GPS data is a relatively new development in the field of environmental determinants of physical activity research. Many opportunities exist in the development of the devices themselves, with device manufacturers developing better technology as the research field progresses and researcher requirements become more advanced.

A mobile phone was found to be an adequate and feasible interface for an eHealth intervention. The

The introduction of accelerometers for objective assessment of physical activity allows valid and reliable evaluations of activity intensity, frequency, and duration. Accelerometers provide objective information on physical activity levels and sedentary behaviour and have the potential for planning health-enhance interventions.

mobile phone applications are easy to learn and use by patients in some clinical situations, patients with with Chronic Obstructive Pulmonary Disease (COPD) including. These applications tested in clinical settings showed a good accuracy of the daily physical activity measurement. The final version of the eHealth intervention is presently being tested for efficacy in these patients in a randomized controlled trial in COPD ${ }^{44}$.

Although many applications relating to physical activity are available from major smartphone platforms, relatively few have been tested in research studies to determine their effectiveness in promoting health. Future studies should utilize randomized controlled trial research designs, larger sample sizes, and longer study periods to establish the physical activity measurement and intervention capabilities of smartphones. There is a need for culturally appropriate, tailored health messages to increase knowledge and awareness of health behaviors such as physical activity ${ }^{45}$.

In relation to GPS, common issues such as satellite acquisition time and better discrimination of indoor activity are already taking place. Newer devices are able to use the quality of the satellite signal alongside the associated noise to discrimi- nate indoor activity. With newer technology, better, more informed decisions can be made, resulting in fewer misclassifications and more accurate findings.

The advancement of GPS research can also take place by eliminating error within the data itself. The elimination of 'bad' data is of significant importance and areas such as cluster detection and mode of transport identification, in addition to trip/journey detection, are all methods that can be used to reduce error in the data as well as increase the quality of the context from which the physical activity derives.

The theoretical foundations of much of the work conducted in this area use an ecological approach, whereby multiple levels influence the behaviour of an individual. Future work can do well to integrate as many of these levels into the research questions/design as possible. It is very important to successfully combine GPS/GIS and SES accelerometry technical components with research questions that investigate not only physical environmental characteristics such as urban/ rural classification, but also important considerations such as obesity gender weekday and weekend patterns and the physical seasons. Attention should also be given to more specific environmental conditions such as weather and daylight length. With newer technologies, better, more informed decisions can be made, resulting in fewer misclassifications and more accurate findings ${ }^{46}$. GPS-measured speed enable the identification of modes of transport. Given the current low costs of GPS devices and the built-in capacity of GPS tracking in most smartphones, the use of such devices in large epidemiological studies may facilitate the assessment of physical activity related to transport modes, or improve exposure assessment using automated travel mode detection ${ }^{47}$. We anticipate more sophisticated modes of activity-sensing technologies for clinical settings and research in forthcoming future.

\section{CONCLUSION}

No single current technique is able to quantify all aspects of physical activity under free-living conditions, requiring the use of complementary methods. The various factors to be considered in 
the selection of physical activity assessment methods in clinical setting and epidemiological studies include sample size, cultural and social/ environmental factors, physical burden for the subject, data logistic and statistical factors, such as accuracy and precision. The choice of method depends predominantly on the aim of the measurement, and the availability of personnel, time and financial resources. A validated questionnaire is usually the preferred method, but when measuring effects this should be combined with an objective measurement instrument ${ }^{48}$.

In the future, physical activity sensors, which are of low-cost, small-sized, and convenient for subjects, epidemiology investigators, and clinicians, will take advantage of consumer technologies to detect location and respond to physical activity in real time, creating new opportunities in measurement, remote compliance monitoring, data logistic, and intervention. Researchers are encouraged to show transparency in their methods. As a relatively new area of research, with everevolving technology, future work is best placed in developing novel, but robust, methods to investigate the physical activity in epidemiological studies and clinical conditions.

Conflicts of interest statement: the authors report no conflicts of interest.

\section{REFERENCES}

1. WHO, Physical activity strategy for the WHO European Region 2016-2025. Regional Committee for Europe 65 ${ }^{\text {th }}$ Session [Internet]. [cited 2016 June 25]. Avaiable from: http://www.euro.who.int/__data/assets/pdf_ file/0010/282961/65wd09e_PhysicalActivityStrategy_150474.pdf/ 2015.

2. Westerterp KR. Assessment of physical activity: a critical appraisal. Eur J Appl Physiol 2009;105:823-8.

3. Trost SG, O'Neil M. Clinical use of objective measures of physical activity. Br J Sports Med 2014;48:178-81.

4. Haskell WL. Physical activity by self-report: a brief history and future issues. J Phys Act Health 2012;9 Suppl 1:S5-10.

5. Mumu SJ, Ali L, Barnett A, Merom D. Validity of the global physical activity questionnaire (GPAQ) in Bangladesh. BMC Public Health 2017;17:650.

6. Craig $\mathrm{CL}$. Evolution and devolution of national physical activity policy in Canada. J Phys Act Health [Internet]. 2011;8. [cited 2018 Jan 3]. Available from: https:// pdfs. semanticscholar.org/5473/da8321a18e379c3a8493e 69b708362b0fe69.pdf.

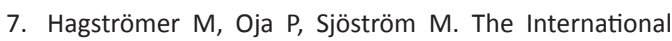
Physical Activity Questionnaire (IPAQ) a study of concu- rrent and construct validity. Public Health Nutr [Internet]. 2006;9. [cited 2018 Jan 3]. Available from: https:// pdfs.semanticscho-lar.org/a9c8/8effafdf27439d76b0ae Obbfe2fa32690d3a.pdf.

8. Bexelius C, Sandin S, Trolle Lagerros Y, Litton JE, Löf M. Estimation of physical activity levels using cell phone questionnaires: a comparison with accelerometry for evaluation of between-subject and within-subject variations. J Med Internet Res [Internet]. 2011;13. [cited 2018 Jan 3]. Available from: https:// www.ncbi.nlm.nih. gov/pmc/articles/PMC3222159/.

9. Van Poppel MN, Chinapaw MJ, Mokkink LB, van Mechelen $\mathrm{W}$, Terwee $\mathrm{CB}$. Physical activity questionnaires for adults: a systematic review of measurement properties. Sports Med 2010;40:565-600.

10. Bauman A, Bull F, Chey $T$, Craig $C L$, Ainsworth BE, Sallis JF et al. The International Prevalence Study on Physical Activity: results from 20 countries. Int J Behav Nutr Phys Act 2009;6:21.

11. Oyeyemi AL, Oyeyemi AY, Adegoke BO, Oyetoke FO, Aliyu $\mathrm{HN}$ et al. The short international physical activity questionnaire: cross-cultural adaptation, validation and reliability of the Hausa language version in Nigeria. BMC Med Res Methodol 2011;11:156.

12. Lee MH, Kim J, Jee SH, Yoo SK. Integrated solution for physical activity monitoring based on mobile phone and PC. Healthc Inform Res 2011;17:76-86.

13. Bull FC, Maslin TS, Armstrong T. Global physical activity questionnaire (GPAQ): nine country reliability and validity study. J Phys Act Health 2009;6:790-804.

14. Mallinson T, Schepens Niemiec SL, Carlson M, Leland N, Vigen $\mathrm{C}$, Blanchard J et al. Development and validation of the activity significance personal evaluation (ASPEn) scale. Aust Occup Ther J 2014;61:384-93.

15. Lee PH, Macfarlane DJ, Lam TH, Stewart SM. Validity of the international physical activity questionnaire short form (IPAQ-SF): A systematic review. Int J Behav Nutr Phys Act 2011;8:115.

16. Çırak Y, Yılmaz GD, Demir YP, Dalkılınç M, Yaman S. Pregnancy physical activity questionnaire (PPAQ): reliability and validity of Turkish version. J Phys Ther Sci [Internet]. 2015;27. [cited 2018 Jan 3]. Available from: https:// www. ncbi.nlm.nih.gov/pmc/articles/PMC4713775/.

17. Baumeister SE, Ricci C, Kohler S, Fischer B, Töpfer C, Finger JD et al. Physical activity surveillance in the European Union: reliability and validity of the European Health Interview Survey-Physical Activity Questionnaire (EHISPAQ). Int J Behav Nutr Phys Act 2016;13:61.

18. Silsbury Z, Goldsmith R, Rushton A. Systematic review of the measurement properties of self-report physical activity questionnaires in healthy adult populations. BMJ open [Internet]. 2015;5. [cited 2018 Jan 3]. Available from: http:// bmjopen.bmj.com/content/5/9/ e 008430 ? utm_source = TrendMD\&utm _ medium $=c p c \& u t m \_c a m p a i g n=B M J O p \_T r e n d M D-0$.

19. Fitzgerald L, Ozemek C, Jarrett H, Kaminsky LA. Accelerometer validation of questionnaires used in clinical settings to assess MVPA. Med Sci Sports Exerc 2015;47: 1538-42.

20. Han B, Cohen DA, Derose K P, Marsh T, Williamson S, Raaen L. Validation of a New Counter for Direct Observation of Physical Activity in Parks. J Phys Act Health 2016;13:140-4. 
21. Gorny AW, Liew SJ, Tan CS, Müller-Riemenschneider F. Fitbit Charge HR Wireless Heart Rate Monitor: Validation Study Conducted Under Free-Living Conditions. [Internet]. 2017;5. [cited 2018 Jan 3]. Available from: https:// www.ncbi.nlm.nih.gov/pmc/articles/PMC5670315/.

22. Brage S, Westgate K, Franks P W, Stegle O, Wright A, Ekelund $U$ et al. Estimation of free-living energy expenditure by heart rate and movement sensing: a doublylabelled water study. PLoS One 2015;10:e0137206.

23. McNamara E, Hudson Z, Taylor SJ. Measuring activity levels of young people: the validity of pedometers. $\mathrm{Br}$ Med Bull 2010;95:121-37.

24. Marigliano E, Fahs PS, Ludden C. Walking for Heart Health: A Study of Adult Women in Rural New York. Creat Nurs 2016;22:268-75.

25. Silcott NA, Bassett Jr DR, Thompson DL, Fitzhugh EC, Steeves JA. Evaluation of the Omron HJ-720ITC pedometer under free-living conditions. Med Sci Sports Exerc 2011;43:1791-7.

26. Scruggs PW. A comparative analysis of pedometry in measuring physical activity of children. Med Sci Sports Exerc 2007;39:1837-46.

27. Scruggs PW. Pedometer steps/min in physical education: Does the pedometer matter? J Sci Med Sport 2013;16:36-9.

28. Kim SY, Park HS. Sources and magnitude of variability in pedometer-determined physical activity levels of youth. J Exerc Rehabil 2015;11:363.

29. Davis MG, Fox KR. Physical activity patterns assessed by accelerometry in older people. Eur J Appl Physiol 2007; 100:581-9.

30. Bento T, Cortinhas A, Leitão JC, Mota MP. Use of accelerometry to measure physical activity in adults and the elderly. Rev Saude Publica 2012;46:561-70.

31. Koolhaas CM, van Rooij FJA, Schoufour JD, Cepeda M, Tiemeier $\mathrm{H}$, Brage $\mathrm{S}$ et al. Objective Measures of Activity in the Elderly: Distribution and Associations With Demographic and Health Factors. J Am Med Dir Assoc 2017;18:838-47.

32. Zhang JH, Macfarlane DJ, Sobko T. Feasibility of a Chestworn accelerometer for physical activity measurement. J Sci Med Sport 2016;19:1015-9.

33. Kamada M, Shiroma EJ, Harris TB, Lee IM. Comparison of physical activity assessed using hip-and wrist-worn accelerometers. Gait Posture 2016;44:23-8.

34. Jung JY, Han KA, Kwon HR, Ahn HJ, Lee JH, Park KS et al. The usefulness of an accelerometer for monitoring total energy expenditure and its clinical application for predicting body weight changes in type 2 diabetic korean women. Korean Diabetes J 2010;34:374-83.

q35. Hart TL, Swartz AM, Cashin SE, Strath SJ. How many days of monitoring predict physical activity and sedentary behaviour in older adults?. Int J Behav Nutr Phys Act 2011;8:62.

36. Herrmann SD, Barreira TV, Kang M, Ainsworth BE. Impact of accelerometer wear time on physical activity data: a NHANES semisimulation data approach. $\mathrm{Br} J$ Sports Med 2014;48:278-82.

37. Plasqui G, Westerterp KR. Physical activity assessment with accelerometers: an evaluation against doubly labeled water. Obesity 2007;15:2371-9.

38. Lee IM, Shiroma EJ. Using accelerometers to measure physical activity in large-scale epidemiological studies: issues and challenges. $\mathrm{Br} J$ Sports Med 2014;48: 197-201.

39. Santos-Lozano A, Marín PJ, Torres-Luque G, Ruiz JR, Lucía A, Garatachea N. Technical variability of the GT3X accelerometer. Med Eng Phys, 2012;34:787-90.

40. Jeran S, Steinbrecher A, Pischon T. Prediction of activity-related energy expenditure using accelerometer-derived physical activity under free-living conditions: a systematic review. Int J Obesity 2016;40:1187-97.

41. Loveday A, Sherar LB, Sanders JP, Sanderson PW, Esliger DW. Technologies That Assess the Location of Physical Activity and Sedentary Behavior: A Systematic Review. JMed Internet Res [Internet]. 2015;17. [cited 2018 Jan 3]. Available from: https://www.ncbi.nlm.nih.gov/pmc/ articles/PMC4705371/.

42. Krenn PJ, Titze S, Oja P, Jones A, Ogilvie D. Use of global positioning systems to study physical activity and the environment: a systematic review. Am Jo Prev Med 2011;41:508-15.

43. Intille SS, Lester J, Sallis JF, Duncan G. New horizons in sensor development. Med Sci Sports Exerc [Internet]. 2012;44. [cited 2018 Jan 3]. Available from: https:// www.ncbi.nlm.nih.gov/pmc/articles/PMC3245518/.

44. Vorrink SN, Kort HS, Troosters T, Lammers JWJ. A Mobile Phone App to Stimulate Daily Physical Activity in Patients with Chronic Obstructive Pulmonary Disease: Development, Feasibility, and Pilot Studies. JMIR Mhealth Uhealth [Internet]. 2016;4. [cited 2018 Jan 3]. Available from: https://www.ncbi.nlm.nih.gov/pmc/articles/PMC4748139/.

45. Coughlin SS, Whitehead M, Sheats JQ, Mastromonico J, Smith S. A Review of Smartphone Applications for Promoting Physical Activity. Jacobs J Community Med [Internet]. 2016;2. [cited 2018 Jan 3]. Available from: https://www.ncbi.nlm.nih.gov/pmc/articles/ PMC4811195/.

46. McCrorie PR, Fenton C, Ellaway A. Combining GPS, GIS, and accelerometry to explore the physical activity and environment relationship in children and young peoplea review. Int J Behav Nutr Phys Act 2014;11:93.

47. Huss A, Beekhuizen J, Kromhout H, Vermeulen R. Using GPS-derived speed patterns for recognition of transport modes in adults. Int J Health Geogr 2014;13:40.

48. Koolhaas CM, van Rooij FJ, Cepeda M, Tiemeier H, Franco $\mathrm{OH}$, Schoufour JD. Physical activity derived from questionnaires and wrist-worn accelerometers: comparability and the role of demographic, lifestyle, and health factors among a population-based sample of older adults. Clin Epidemiol 2017;10:1-16. 